\title{
Business Continuity for Clinical Laboratories Affected by Earthquakes
}

\author{
Joanne M Deely*1, Thomas J Huggins ${ }^{2}$, Sandra Richardson ${ }^{1,3}$ and Peter George ${ }^{1}$ \\ ${ }^{1}$ Canterbury District Health Board, Christchurch, New Zealand \\ ${ }^{2}$ Massey University, Wellington, New Zealand \\ ${ }^{3}$ University of Canterbury, Christchurch, New Zealand \\ *Corresponding author: Joanne M Deely, Canterbury District Health Board, Christchurch, New Zealand
}

\section{ARTICLE INFO}

Received: 画 March 04, 2020

Published: 㠦 March 11, 2020

Citation: Deely J M, Huggins T J, Richardson S, George P. Business Continuity for Clinical Laboratories Affected by Earthquakes. Biomed J Sci \& Tech Res 26(3)-2020. BJSTR. MS.ID.004365.

Keywords: Business Continuity; Clinical Laboratories; Case Study; Earthquake; Secondary Analysis

\section{ABSTRACT}

Purpose: Without disaster-related business continuity planning, critical health sector components are unlikely to function during and following a major disaster. This is particularly relevant for clinical laboratories which form an indispensable part of an operational health system. The current case study highlights the business continuity measures employed by laboratories in Christchurch, New Zealand, to manage and mitigate challenges they faced following a major earthquake in 2011.

Approach: A framework of business continuity measures was applied to laboratory operations data prior to and following the 2011 earthquake. The framework included: Staffing and Personnel, Operations, Records \& Databases, Communications, and Logistics.

Findings: Each of three laboratory businesses was faced with a wide range of business continuity issues throughout the response and initial recovery phases. Some of these issues were able to be addressed as a result of both prior planning and subsequent attention to emerging challenges. However, the business continuity of each laboratory was largely dictated by wider organizational and health system capacities.

Practical Implications: The results demonstrated the value of using established business continuity criteria to deal with unforeseen problems. Clinical laboratories should prioritize their engagement with such criteria, as part of their overall health sector strategy. This will help mitigate substantial stress and long-term disruptions faced by laboratories without a pre-existing, practiced and implemented, business continuity plan.

Originality: The current research adds to a relatively scarce body of literature on business continuity in the health sector. It offers a starting point for academic literature concerning the specific business continuity of clinical laboratories, within a wider set of resilience considerations.

\section{Introduction}

Continuity of clinical laboratory services is essential postdisaster to avoid the wider health system failing. Although laboratory-related costs amount to less than 5 percent of a typical hospital's budget, 60 to 70 percent of all critical clinical decisions, including admission, discharge, and drug therapy can depend on clinical laboratory services $[1,2]$. In the absence of clinical laboratory testing, hospitals face substantial delays for acute and complex diagnoses, including diagnosis of acute conditions caused by the disaster; for example, hyperkalemia caused by crush injury. Non-acute patient medication management such as the prothrombin time/ international normalized ratio (PT/ INR) testing for warfarin blood levels can also be substantially delayed, potentially threatening the mortality of patients. Given the fundamental need for rapid transport and other logistical arrangements [3], laboratory testing may even cease under certain 
logistical conditions. Health sectors play a vital role caring for casualties and maintaining public health in the crises that often characterize disaster-affected contexts.

However, this vital role is often compromised if the health sector is within the disaster zone. The potential frailty of health sector infrastructure was highlighted by hospital failures following Hurricanes Katrina in 2005 [4,5] and in 2008/2009, when ice storms jeopardized the lives, health and wellbeing of large USAbased populations in the absence of many important health services [6]. The un-mitigated effects of the Hurricane Katrina and ice storm disasters included complete power outages and completely inoperable hospital infrastructure [6]. These catastrophic failures occurred at a time when emergency departments and other health infrastructure were most urgently required. Business continuity planning is a paramount concern for health sector agencies. Business continuity has been defined as: '...not solely about planning for the next sudden influx of patients (a surge plan) but also is about an integrated approach in preparing for a wide variety of events that may harm biomedical and IT systems, the physical plant, patients and staff [6].

Devlen 2009 provided a framework for business continuity planning in the health sector, to help mitigate and prepare for a range of disaster-related risks [6]. Two important business continuity measures that apply to clinical laboratories include: ordering tests and reviewing results. More generic considerations include staffing and personnel, operations, records and databases, communications, and logistics. In the context of Devlen's framework of business continuity, we review the measures taken by laboratories in Christchurch, New Zealand, to manage and mitigate the challenges they faced following a major earthquake in 2011. Several of these measures were taken prior to the 2011 earthquake. Other elements of business continuity planning were carried out in the post-earthquake context, after specific needs and priorities had been identified.

\section{The Post-Earthquake Canterbury Context}

The 22 February 2011 Christchurch earthquake provides a valuable case study of business continuity and dis-continuity within an integrated health system [7]. This earthquake closely followed a previous earthquake that occurred on the 10 September 2010, in the early hours of the morning. The first earthquake, known as the Darfield earthquake, registered a magnitude of $7.1 \mathrm{Mw}$ and gave rise to a total of at least 2,256 injuries registered with the New Zealand government's Accident Compensation Corporation [8]. It caused substantial damage to buildings and other built infrastructure [9] and set off a sequence of liquefaction that would further affect the integrity of built infrastructure throughout the region [10]. The second event known as the Christchurch earthquake, occurred at 1251 hours on the 22 February 2011. Although this earthquake registered a much smaller magnitude of 6.3 Mw, it included the highest vertical acceleration ever recorded during an earthquake event [11]. The force of this vertical acceleration was largely directed at the central business district of Christchurch City, causing severe structural damage. Within the first 24 hours, the Canterbury population of approximately 400,000 people suffered a total of 182 deaths, and 6659 injuries requiring medical care [11]. Two further deaths occurred during the following weeks. The local population suffered a total of 7,171 injuries that were attributed to the Christchurch earthquake [8].

Both earthquakes placed substantial demands on the Canterbury health system [7]. The 2011 earthquake was particularly demanding for a health board catchment with a primary hospital capacity of only 600 to 650 beds at Christchurch Hospital and a pre-earthquake rate of approximately 220 patients received per day [11]. Immediately following the earthquake, Christchurch Hospital received a mass influx of injured patients, while periodically losing power to clinical areas of its emergency department, intensive care unit, blood service, and radiology department [11]. Hospital stairwells lift access and surrounding roads were rendered unserviceable. Communications between emergency services and health sector agencies far exceeded capacity. Christchurch Hospital was left with very little information about the scale or growing implications of the earthquake and subsequent aftershocks [11]. During the following months and years, in response to these and other emerging demands on health system capacities, the Canterbury District Health Board (CDHB) accelerated implementation of their integrated health system initiative. Broadly, this initiative aimed to meet "the needs of all people whom the general practice team would have otherwise referred to hospital, but who could be safely managed in the community" [12]. It was hoped that this overarching goal and others would be achieved by: supporting people to take increased responsibility for their own health; primary care services supporting people in a community-based setting; ensuring that secondary care-based specialist resources could respond to episodic events and more complex cases, and to needs for advice in primary care health and community settings [12].

\section{Clinical Laboratories in the Case Study Context}

In a health sector context, resilience is the ability to adjust "functioning prior to, during, or following changes and disturbances, so that it can sustain required operations under both expected and unexpected conditions" (Resilient Health Care Net, 2017). Christchurch's clinical laboratories were one component of health sector resilience, when jeopardized, could make the transforming Canterbury health system both less resilient and more vulnerable to failure. This component of health system resilience was challenged by the Canterbury earthquakes [7]. Clinical laboratories throughout Canterbury suffered from numerous impacts on their capacity to deliver life-saving services, from the immediate to the medium-term aftermath. As outlined below, these post-earthquake impacts followed a sequence of disruptions to clinical testing for the Canterbury region. At the time of the earthquake, the New Zealand Ministry of Health was responsible for funding most diagnostic testing via district health boards. Diagnostic testing within the Canterbury region was funded via the CDHB and was carried out at three different laboratories. Southern Community Laboratories (SCL), owned by Healthscope New Zealand, and Med Lab South (MLS), owned by Sonic Healthcare, were commercial laboratories contracted by CDHB to test and screen generally healthy populations, or patients managing illnesses at home. 
These two laboratories also catered to primary care doctors (general practitioners), midwives, aged residential care facilities, and private hospitals. One other laboratory, Canterbury Health Laboratories (CHL) was a business entity within the CDHB that served public hospitals including: Christchurch Hospital, Christchurch Women's Hospital, Burwood Hospital, and The Princess Margaret Hospital. CHL had the chief responsibility for assisting with the diagnosis of acutely ill patients and for determining the causes of unexplained deaths, including cases referred by the coroner. Despite a clear division of responsibilities, and total testing capacities which could cover almost double the population of their catchment (Martin Langridge, MLS, personal communication, June 19, 2015), the two community clinical laboratories had been under financial strain. The laboratories had typically offered incentives to clients in return for increased testing. This use of incentives helped each laboratory to better exploit their capacities for testing. However, incentives had also led to unnecessary testing and unnecessary screening of healthy patients. In response to surrounding issues, a national schedule for testing was set [13]. CDHB ruled-out competitive incentives and community contract pricing became fixed at a set rate [7].

By 2011, fixed prices for community testing had not changed for a number of years although the price of testing materials and other related costs had been steadily increasing. Profit margins were falling as a result. MLS, who had 65 percent of the community market, had taken on additional testing for acutely ill communitybased patients (Martin Langridge, MLS, personal communication, June 19, 2015). Although this type of testing was costlier than the remainder of their testing contract, fixed pricing meant that MLS were not able to pass those costs on to the CDHB. MLS stopped

Table 1: Business Continuity Considerations* weekend testing in an effort to remain profitable. They also reduced staff, reduced section-specific budgets, and consolidated satellite operations to within a single Christchurch laboratory. The biggest challenge for CHL before the earthquake was coping with industrial action by the Medical Laboratories Workers Union (Kirstin Beynon, CHL, personal communication, 19 February 2017; Radio New Zealand [14]). Their strike continued through to the day of the 2011 earthquake. Many of CHL's laboratories were left with half of their usual staff, meaning that leave for conferences and out of town meetings had to be cancelled (Kirstin Beynon, CHL, personal communication, 19 February 2017). At the time of the 2011 earthquake, the laboratory was operating on limited staff and going through a period of considerable tension with exhausted staff, and stressed section managers.

The 2011 earthquake further compounded the pre-existing financial and staffing difficulties outlined above. Buildings occupied by CHL were badly damaged and community laboratories run by SCL and MLS were effectively destroyed. This meant that CHL became the only service operating in the first week. Many testing clients lost power or computer capability in the immediate aftermath or had their premises destroyed. The relocation of clients created their own set of logistical challenges in the medium term, as did the reallocation of SCL and MSL's services. The remainder of this paper outlines how the three clinical laboratories managed or struggled to manage these eventualities and others. Operational data from the Canterbury District Health Board and each of the laboratories involved, together with excerpts from personal communications, are used to illustrate how the laboratories managed their business continuity.

\begin{tabular}{|c|c|}
\hline Category & Considerations \\
\hline Staffing \& Personnel & $\begin{array}{c}\text { Reduce loss of life, damage and losses } \\
\text { Plan to maintain essential staffing, including contractors } \\
\text { Plan for staff losses, alternative scheduling and reduced demands } \\
\text { Evaluate and manage onsite and offsite staffing deployment } \\
\text { Make arrangements for childcare, overnight stays and extra shifts } \\
\text { Develop flexible leave options catering for family needs } \\
\text { Evaluate and manage health and safety issues } \\
\text { Plan to re-deploy staff as needed, offer staff training in specific areas } \\
\text { Address issues with unions concerning changing work demands } \\
\text { Assess core competencies and cross-train for similarities } \\
\text { Regularly train staff in contingency planning and emergency planning }\end{array}$ \\
\hline Operations & $\begin{array}{l}\text { Identify critical points, functions or processes } \\
\text { Plan to reduce services while prioritizing critical functions } \\
\text { Evaluate health and safety issues related to new and lost roles } \\
\text { Assess legal liabilities } \\
\text { Plan timely recovery to resume full service delivery }\end{array}$ \\
\hline
\end{tabular}




\begin{tabular}{|c|r|}
\hline Records \& Databases & $\begin{array}{c}\text { Ensure protection of operational, legal and financial records. } \\
\text { Back-up databases off-site }\end{array}$ \\
\hline Communications & $\begin{array}{r}\text { Evaluate the interoperability of cell phones and other communications } \\
\text { Make phone numbers and other contact information available to staff } \\
\text { Include details for contacting core external partners } \\
\text { Plan to provide written or verbal updates to all personnel }\end{array}$ \\
\hline Logistics & Schedule resourcing and provision support services \\
& Make flexible transport arrangements.
\end{tabular}

Note: *Adapted from: Considerations for Hospital Business Continuity, Devlen [6].

Table 2: Overview of Major Challenges Faced.

\begin{tabular}{|c|c|c|c|}
\hline Aspect & Southern Community Laboratories & Med Lab South & Canterbury Heath Laboratories \\
\hline Building & $\begin{array}{l}\text { Destroyed - recovered services } \\
\text { supported by other SCL labs. }\end{array}$ & $\begin{array}{l}\text { Destroyed - recovered services in } \\
\text { alliance with CHL. }\end{array}$ & Minor damage. \\
\hline Services & Recovered within days & Recovered within weeks & \multirow{2}{*}{$\begin{array}{c}\text { Recovered core services within } \\
\text { hours. }\end{array}$} \\
\hline Equipment & Lost all equipment and analysers & $\begin{array}{l}\text { Eventually recovered all building } \\
\text { contents. }\end{array}$ & \\
\hline Staff Availability & $\begin{array}{l}\text { Limited due to circumstances of } \\
\text { quake. }\end{array}$ & $\begin{array}{l}\text { Limited due to circumstances of } \\
\text { quake. }\end{array}$ & $\begin{array}{l}\text { Limited due to circumstances of } \\
\text { quake and industrial strike action }\end{array}$ \\
\hline Specialist Laboratories & No specialist laboratories & No specialist laboratories & $\begin{array}{c}\text { Loss of scientists with } 30 \text { years' } \\
\text { experience. This potentially } \\
\text { jeopardised accreditation. }\end{array}$ \\
\hline Specimens & $\begin{array}{l}\text { Most blood samples lost. Some } \\
\text { pathology and histology samples } \\
\text { retrieved. }\end{array}$ & $\begin{array}{l}\text { Most blood samples lost. Most } \\
\text { pathology and histology samples } \\
\text { retrieved. }\end{array}$ & No samples lost. \\
\hline Records & $\begin{array}{l}\text { Electronic records recovered within } \\
\text { days. } \\
\text { All paper records lost. }\end{array}$ & $\begin{array}{l}\text { Electronic records recovered within } \\
\text { days. } \\
\text { All paper records lost. }\end{array}$ & $\begin{array}{c}\text { Computer server and infrastructure } \\
\text { undamaged. } \\
\text { No paper records lost }\end{array}$ \\
\hline Accessioning and Sample Coding1 & $\begin{array}{c}\text { Compatible with MLS } \\
\text { but not with CHL }\end{array}$ & $\begin{array}{l}\text { Compatible with SCL but not with } \\
\text { CHL. }\end{array}$ & Not compatible with MLS or SCL. \\
\hline Specimen Tubes for Auto-Analysers & $\begin{array}{c}\text { Supplied by Roche } \\
\text { Not compatible with CHL }\end{array}$ & $\begin{array}{l}\text { Supplied by Roche } \\
\text { Not compatible with CHL }\end{array}$ & $\begin{array}{c}\text { Supplied by Abbott } \\
\text { Not compatible with MLS or SCL }\end{array}$ \\
\hline $\begin{array}{c}\text { Computer Server and Operating } \\
\text { System }\end{array}$ & $\begin{array}{l}\text { Unix with Ultra. } \\
\text { Compatible with MLS. }\end{array}$ & $\begin{array}{l}\text { Unix with Ultra. } \\
\text { Compatible with SCL. }\end{array}$ & $\begin{array}{l}\text { Unix with Delphic. } \\
\text { Compatible with NZ DHB hospitals } \\
\text { but not MLS or SCL. }\end{array}$ \\
\hline Support Laboratory & $\begin{array}{l}\text { SCL laboratories in Dunedin and } \\
\text { Auckland }\end{array}$ & CHL & MLS \\
\hline Outpatient Specimen Collection & $\begin{array}{l}\text { SCL outpatient centres re-opened } \\
\text { on the second day }\end{array}$ & $\begin{array}{l}\text { MLS outpatient centres re-opened } \\
\text { within days }\end{array}$ & $\begin{array}{l}\text { CHL outpatient centre remained } \\
\text { open. Hospital theatres and } \\
\text { outpatients shut for two weeks. }\end{array}$ \\
\hline
\end{tabular}

${ }^{1}$ System used to register and track patient samples.

\section{Approach}

The current case study uses personal accounts and secondary data concerning how clinical laboratories operated before, during and after the 2011 Canterbury earthquake. Each of the affected laboratories has consented to use of their data. Operational data from the CDHB have been complemented with excerpts from personal communications with laboratory and CDHB managers. Table 1 shows an adaptation of Devlen's framework for business continuity to fit laboratory services post disaster. Ordering tests and reviewing results are particularly important for clients of clinical laboratories. The health system has electronic ordering and results are sent electronically to clients. This means that turn-around times can be accurately measured from the time when tests are ordered to the time when results are sent to clients [15]. Other considerations shown in Table 1 were selected according to the availability of relevant operational data. The schema shown in Table 1 was used to structure an account of business continuity and dis-continuity for clinical laboratories operating in post-earthquake Canterbury. 


\section{Results}

The following section uses personal communications with key management personnel and complementary data to show how some of the considerations outlined in Table 1 were addressed prior to the 2011 earthquake. However, despite careful planning, none of the affected laboratories foresaw the full extent of challenges they would face. Consequently, although both MLS and CHL had developed business continuity plans, many challenges were addressed as they arose in the post-disaster context. Table 2 provides a summary of challenges faced by the three clinical laboratories in the aftermath of the 2011 Christchurch earthquake. The remainder of this Results section categorizes these and other details into the adapted business continuity framework outlined in Table 1.

\section{Staffing \& Personnel}

Even though there are some laboratory processes that can be automated, each laboratory depended on a group of highly specialized and skilled professionals. They also had many processes to ensure that these professionals could depend on support from each laboratory organization.

CHL: According to Gullery, et al. [12], the CDHB had experienced an increase of approximately 25 percent in acute admissions between January 2009 and January 2011. There had been an increase of approximately 8 percent in CDHB emergency department attendances over the same period [16, 17]. Over the short and medium term, this rapid growth in admitted patients and emergency department attendances had placed ongoing pressure on CHL personnel to complete more testing with the same resources. At the time of the earthquake, CHL had an international team of experts in lean processes on-site to train a team of CHL staff to streamline lab processes and systems. The earthquake left CHL labs in a state of disarray, with no power or water utilities and a shortage of staff. Within the main laboratory building on Hagley Avenue, light fittings and large heavy roof tiles had dropped into the hallways, offices, and laboratories [7]. The floor spaces were covered in broken glass, equipment, books, reagents, and general mess everywhere, as shown in Figures $1 \& 2$. There was a noxious smelling chemical spill in the toxicology lab. Analyzers and instruments, microscopes, water baths, and fume cupboards had been ripped from the walls and fallen onto floors; computers had fallen from desks; water pipes had burst, and one laboratory was flooding. Most staff were evacuated to outside the building where they assembled in the car park area and waited for most of an hour before being sent home. During the afternoon of 22 February, while the core laboratories were still being re-established, CHL negotiated with the Medical Laboratories Union to postpone further strike action. On 23 February 2011, MLS's operations manager joined CHL managers in the operations room to plan integration of MLS's community services and staff within CHL. Improved interactions with the union and integration with MLS proved essential to meet continuing and rising demands for laboratory tests. Test numbers for CDHB inpatients continued to increase throughout 2011 and 2012 [15].

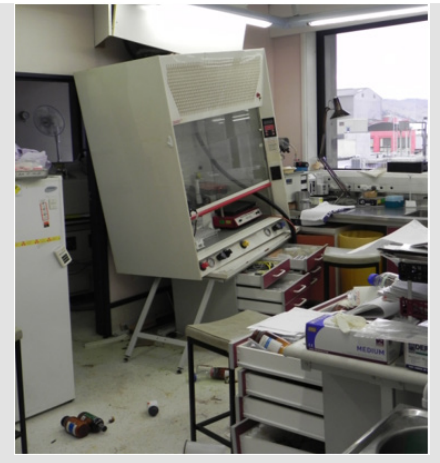

Figure 1: Damage inside Canterbury Health Laboratories (Chris Florkowski, Canterbury District Health Board).

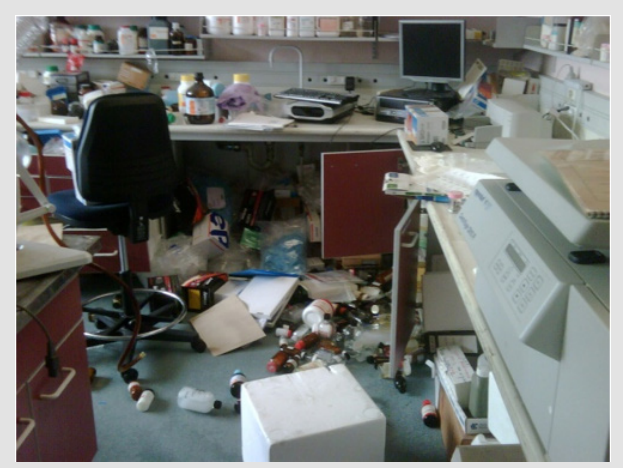

Figure 1: Further damage inside Canterbury Health Laboratories (Chris Florkowski, Canterbury District Health Board).

MLS: Personnel wellbeing and safety became the priority immediately following the earthquake, which destroyed MLS's main laboratories in the central business district. After fully evacuating their main premises, MLS set up a 0800 (toll free) telephone number for staff to call for earthquake related support (Gordon Sutton, SCL, formerly MLS, personal communication, May 2, 2014). They also set up a Facebook group and educated staff about earthquake safety behavior. Despite these efforts, MLS went on to face a number of emerging challenges to the wellbeing of their managers and other personnel. Laboratory workers were subsequently relocated to CHL, at a separate site from their senior managers (Tom Henderson, CHL, formerly MLS, personal communication, 9 April 2014). MLS middle management roles were no longer necessary, due to CHL oversight and coordination (Anja Werno, CHL, personal communication, 11 April 2014). Middle managers assumed a range of technical and manual roles instead (Gordon Sutton, SCL, formerly MLS, personal communication, 2 May 2014). Among other elements, these staffing and personnel changes led to some conflict between MLS and CHL management (personal communication, Anja Werno, 11 April 2014; Gordon Sutton, 2 May 2014). 
SCL: Staff and patient safety were also the priority for SCL immediately following the 2011 earthquake. They immediately carried out a complete and permanent evacuation of their building. Despite four relocations over the following 16 months, SCL kept a total of 50-75 personnel on their laboratory payroll (Iona Laurie, SCL, personal communication, June 18, 2015).

\section{Operations}

Laboratory operations concern processes that personnel implement in order to maintain service delivery. As outlined in Table 1, this includes: reducing services while prioritizing critical functions; evaluating emerging health and safety issues related to new and lost roles; assessing legal liabilities; and eventually returning to full-service delivery. Table 3 provides a summary of relevant actions taken. Some of these aspects are expanded on, in the remainder of this sub-section.

CHL: Prior to the earthquakes, the three clinical laboratories operating in Canterbury had a capacity to service approximately 1.4 million people in a catchment of 500,000 to 600,000 people (Michael O'Dea, Canterbury Earthquake Authority, personal communication, 20 June 2014). All three laboratory services had reviewed their disaster contingency plans following the 2010 earthquake. Among other factors, a general surplus of operational capacity also added to peace of mind for each laboratory. The CHL Mortuary became a critical service on the day of the earthquake, with space for 48 deceased people (Rod Smith, CHL, personal communication, April $10,2014)$. The region covered by the hospital mortuary included the West Coast province, and Timaru and Kaikoura townships. Within several hours of the earthquake, it was estimated that at least 5060 people had been killed in the disaster. It became clear that there would not be enough space, given that routine work also needed to continue (Rod Smith, CHL, personal communication, April 10, 2014). A temporary mortuary was set up at the Christchurch police station until the Disaster Victim Identification (DVI) squad arrived and the temporary mortuary was moved to Burnham Military Camp - 30 kilometers south of Christchurch. The DVI process commenced on Friday evening on the 25 February 2011 and all 185 autopsies were completed within eight days. The normal death rate, from accidents and suicides, dropped to zero from the usual rate of 6 to 12 per month, which alleviated the mortuary workload for the following months.

The Biochemistry Laboratory was critical for hospital care, with all testing normally automated on a 24-hour basis (Lesley Stuart, CHL, personal communication, March 7, 2014). During the shaking, two immunoassay analyzers and two c8000 Abbott chemistry analyzers were on an automatic track. These analyzers stopped when power was lost. It took an hour to restart them and complete quality checks which found that one of the chemistry analyzers was temporarily unstable. The Biochemistry Laboratory was fully functioning by 1830 hours local time. Many results were still delayed by a couple of hours due to power outages at the hospital and servicing of the pneumatic tube (which delivered specimens from the hospitals to CHL). Despite remaining open, CHL's blood collection center did not receive any patients on the day of the earthquake. CHL went on to experience a general decrease in demand for blood testing in the early weeks. Immediately after the earthquake, hospital surgery lists were cancelled, and outpatient clinics closed to release medical personnel and theatres for earthquake casualty surgery and care. CHL normally received around 2000 specimens per day before the earthquake. On the 22 February 2011, this number dropped to 1700 before dropping further to 1000 specimens on the 23 February. Testing for hospitals and outpatients did not reach normal levels again for several weeks. There was also a sudden drop in testing for the community because many primary care practices were closed. This decrease in testing was experienced by all three laboratories and continued until CHL received an influx of MLS community testing from around 48 hours after the earthquake.

MLS: All MLS blood collection centers reopened within the first week following the earthquake. In the meantime, an emergency control center was set up at the chief executive officer's home on the 23 February. Following short to medium term arrangements outlined in Table 3, the MLS cytology team was allocated their own premises within Christchurch. Cervical screening and other services remained outside of CHL. MLS staff remained at CHL until a new service alliance contract between CDHB and SCL and CHL came into effect on the 14 June 2012.

SCL: SCL recovered their operational capability within a week after the earthquake. Laptops were retrieved from the SCL building once all personnel and patients had been evacuated. By the end of the first week, between 900 and 1000 specimens were being couriered daily, for testing within three hours' drive of Christchurch. At this stage, all non-blood pathology specimens and supplies had been recovered from the damaged building and all SCL blood collection centers were fully operational (Jan Parker, SCL, personal communication, June 3, 2015). At the time of the earthquake, SCL had been responsible for 30 percent of community testing within Canterbury. They went on to win the community portion of the alliance contract with the CDHB in December 2011 and their parent company, Healthscope, went on to purchase competing laboratories. This led to SCL absorbing staff from other commercial laboratories while taking over entire laboratories in Nelson, Blenheim and Timaru. Within 16 months of the earthquake, SCL had built and fitted out a new laboratory, purchased competing laboratories, and tripled the overall size of their service. 
Table 3: Actions Taken to Address Operational Continuity.

\begin{tabular}{|c|c|c|c|}
\hline Action & CHL & MLS & SCL \\
\hline $\begin{array}{l}\text { Critical operation points, functions } \\
\text { or processes identified }\end{array}$ & $\begin{array}{l}\text { Clean water sourced from on-site } \\
\text { well, and emergency power from } \\
\text { back-up generators. }\end{array}$ & Alliance contract with CHL. & $\begin{array}{l}\text { All essential equipment recovered } \\
\text { from building. }\end{array}$ \\
\hline $\begin{array}{l}\text { Service reduction planned to } \\
\text { address needs, critical functions } \\
\text { and other factors }\end{array}$ & $\begin{array}{l}\text { Critical priority was service } \\
\text { delivery to Christchurch Hospital. } \\
\text { Following the quake, focused on } \\
\text { delivering rapid diagnosis for } \\
\text { earthquake casualties. All out-of- } \\
\text { town work cancelled for first week. }\end{array}$ & $\begin{array}{l}\text { Core staff and services blended into } \\
\text { CHL within initial three weeks. }\end{array}$ & Planned but not required. \\
\hline $\begin{array}{l}\text { Emergent health and safety issues } \\
\text { evaluated }\end{array}$ & $\begin{array}{l}\text { Most staff evacuated from building. } \\
\text { Core lab staff remained inside to } \\
\text { reboot analyzers }\end{array}$ & $\begin{array}{c}\text { All staff evacuated. Histology } \\
\text { and pathology staff relocated to } \\
\text { Auckland branch. }\end{array}$ & $\begin{array}{l}\text { All staff evacuated. Essential } \\
\text { operations accommodated in } \\
\text { facilities outside of earthquake } \\
\text { affected building. }\end{array}$ \\
\hline $\begin{array}{l}\text { Timely recovery and resumption of } \\
\text { service delivery }\end{array}$ & $\begin{array}{l}\text { Cores services resumed within } \\
\text { hours: Blood Transfusion } \\
\text { Service, Mortuary, Registration, } \\
\text { Biochemistry Laboratory, } \\
\text { Hematology Laboratory. }\end{array}$ & $\begin{array}{l}\text { Recovery achieved within } 3 \text { of } \\
\text { the earthquake, as planned for } \\
\text { in collaboration with CHL and } \\
\text { arrangements with other MLS } \\
\text { branches. }\end{array}$ & $\begin{array}{l}\text { Shifted testing to other SCL and } \\
\text { parent company sites resulted in } \\
\text { uninterrupted service delivery. }\end{array}$ \\
\hline
\end{tabular}

\section{Records and Databases}

Information technology infrastructure for records and databases were a key consideration for CHL, MLS and SCL laboratories. However, each laboratory faced a very different set of relevant demands.

CHL: CHL provides a 24-hour service, seven days a week. This meant they already had all electronic services and utilities, including servers, backed-up offsite before the 2011 Christchurch earthquake. CHL's on-site computer infrastructure remained intact regardless and was restarted immediately, using power from the hospital's back-up generators. Although air conditioning had broken down on-site, the computer servers were in a room with a window and could be cooled by natural air flow.

MLS: MLS were in the process of backing up their main database server in a secure bunker when the 2011 earthquake struck. MLS's computer servers were physically retrieved following the earthquake and placed in secure server housing at another site in the city on Friday the 25 February 2011.

SCL: Within a week after the 2011 earthquake, essential computer data had been physically retrieved from the evacuated SCL building and uploaded to an Auckland-based server. SCL lost all blood specimens because their building was designated for demolition as a contaminated site. However, rescued computer data had records of where the specimens came from. This allowed SCL to resume testing of the patients with missing specimens.

\section{Communications}

Communications were an important part of responding to, and recovering from, the 2011 earthquake. Relevant arrangements were made by each of the laboratories and these arrangements have been documented to varying extents.

CHL: CHL set up a control room on the day of the 2011 earthquake. This is where senior management of CHL led recovery of their labs for the public hospitals, recovery of their specialist national referral lab services, and recovery of services formerly provided by MLS. The control room was set up with computers and telephones and each senior manager was allocated their own area of responsibility. The control room was linked to the citywide disaster response via teleconferences with the New Zealand Police, Civil Defence and Emergency Management, primary care practitioners (general practitioners), suppliers, and other agencies and partners. Rapid communication up and down the CDHB organizational hierarchy allowed CHL to double their operational capacity within weeks. A daily meeting was held between senior managers and staff during the first weeks where management provided updates on changes taking place and staff could raise their concerns. Section heads emailed written reports to senior managers daily on a range of topics, including staff welfare.

MLS: MLS remained in communication with their out-of-town laboratories via their re-housed computer systems. This was an important part of resuming their services as an integrated part of health services provided by the CDHB.

SCL: SCL enjoyed robust communications both vertically and horizontally, within SCL Christchurch and other SCL areas across New Zealand. SCL focused on disseminating news about new buildings and new locations being organized by Christchurch and South Island managers (Jan Parker, SCL, personal communication, June 3,2015$)$. This appears to have been one of their efforts to maintain staff morale and retain valuable personnel.

\section{Logistics}

Like communications, logistical arrangements have been documented to varying extents. Table 4 provides a summary of relevant actions carried out by each of the laboratories and the remainder of this sub-section provides further details. 
Table 4: Actions Taken to Address Logistical Continuity.

\begin{tabular}{|c|c|c|c|}
\hline Action & CHL & MLS & SCL \\
\hline Scheduled resourcing & $\begin{array}{c}\text { Biochemistry and Hematology labs } \\
\text { were identified as a priority service } \\
\text { for disaster response. Resourced } \\
\text { with a steady supply of reagents, } \\
\text { other supplies, instruments, and } \\
\text { analyzers. }\end{array}$ & $\begin{array}{c}\text { Resourced via collaboration with } \\
\text { CHL. }\end{array}$ & $\begin{array}{c}\text { Insurance paid all costs associated } \\
\text { with transporting and testing } \\
\text { specimens outside of Christchurch. }\end{array}$ \\
\hline Support services provisioned & $\begin{array}{c}\text { Range of supports provided as } \\
\text { part of integrated health system } \\
\text { initiative. }\end{array}$ & $\begin{array}{c}\text { Range of supports provided as part } \\
\text { of collaboration with CHL. }\end{array}$ & $\begin{array}{c}\text { SCLs computer network was } \\
\text { distributed on a nationwide } \\
\text { platform that could be accessed at a } \\
\text { range of remote sites. }\end{array}$ \\
\hline Flexible transport arrangements & Not required. & $\begin{array}{c}\text { Retrieved specimens, records } \\
\text { and equipment from inside the } \\
\text { military cordons by driving marked } \\
\text { laboratory vehicles, befriending the } \\
\text { military guards, and using police } \\
\text { escorts. }\end{array}$ & $\begin{array}{c}\text { Specimens couriered to Ashburton } \\
\text { three times daily and other } \\
\text { specimens sent to Dunedin by air. } \\
\text { Fleet of bicycle couriers traversed } \\
\text { earthquake-damaged roads to } \\
\text { extend the stretched courier } \\
\text { capacities. }\end{array}$ \\
\hline
\end{tabular}

CHL: Daily meetings between senior managers allowed CHL to rapidly determine additional resourcing needs. The general manager would send a daily report on the situation and the laboratories' requirements to CDHB's Chief Executive Officer. This rapid reporting structure led to prompt decisions unencumbered by the normal administrative processes. For example, a new c16000 Abbott chemistry analyzer arrived in the Biochemistry Laboratory on the 2 March 2011, almost doubling the capacity of the Biochemistry Laboratory. The CHL store was so well supplied that it could redistribute its supplies to primary care doctors in the community during initial response and recovery (Sue Carnoutsos, CHL, personal communication, March 7, 2014).

MLS: MLS faced the logistical challenge of retrieving specimens and equipment from their main business premises. These premises were in the cordoned off central business district, where most of the 185 earthquake fatalities occurred. Some of the 185 deceased were still not accounted for when MLS's computer servers were being retrieved from the damaged building, along with hundreds of histology and cytology specimens. Auto-analyzers continued to run on back-up batteries after the earthquake until they ran out. These results were eventually approved and sent to customers.

SCL: SCL's biggest logistical challenge was finding operational premises in the absence of financial certainty. In the immediate aftermath, there was no guarantee that SCL would win the alliance service contract with CDHB, which was essential for the viability of their Canterbury operations. SCL went on to change temporary premises at least four times within 16 months. The first location was particularly challenging for staff. It was the unfinished endoscopy suite of Southern Cross Hospital with no wall linings, no roof linings, a concrete floor, and no running water. The roof leaked and there was no heating or toilets. The entire premises were initially outfitted with only two power points [7]. The building was nonetheless protected from repeated aftershocks because it was built on movable foundations. Water for the improvised endoscopy laboratory was transported in 40-liter containers to Christchurch from Dunedin located 310 kilometers south of Christchurch [7].
During this time couriers brought specimens from around the city to the SCL endoscopy room where they were sorted and centrifuged before transport to Dunedin for analysis. During the initial six weeks following the earthquake, all tests were completed in Dunedin.

SCL blood collection centers experienced a generally low demand for blood testing following the earthquake. However, several patients arrived at the centers for the international normalized ratio index of blood coagulability (INR) testing, to help manage their levels of warfarin medication. INR testing is required on the day of blood collection, so specimens were flown to SCL's Dunedin City lab for urgent analysis. The distributed design of SCL information technology meant that INR results could be reported from Dunedin to Christchurch doctors on the same day that specimens were collected. A coagulation analyzer for INRs and a main biochemistry analyzer were soon set up in SCL's Ashburton laboratory about $100 \mathrm{~km}$ south of Christchurch. INR analysis was eventually transferred back to Christchurch. In the middle of 2011, SCL set up biochemistry and hematology services in Princess Street, close to the center of Christchurch City. Histology services were set up in Gribbles Veterinary Laboratory in Christchurch and Microbiology was set up in Christchurch's RJ Hills Laboratories. The core laboratory stayed in Princess Street for about a year and then moved to Print Place, which was slightly further from the city center. SCL stayed in Print Place for three months of 2012 before they built a dedicated lab on Logistics Drive, near Christchurch's airport.

\section{Discussion}

After the Christchurch earthquake, business continuity was important for Christchurch's clinical laboratories; it enabled them to maintain delivery of acute and non-acute healthcare services. It enabled CHL's laboratories to respond to a sudden influx of community testing, MLS to operate most of its services in collaboration with CHL, and SCL to operate in changing locations supported by the wider organisation. Devlen [6] highlighted several failures in business continuity, during health sector responses to 
hurricane and ice storm disasters in the United States of America. Devlen developed a framework of business continuity planning, to help avoid many of these failures. The current paper applied the resulting framework to clinical laboratories operating in the aftermath of the February 2011 earthquake in Canterbury, New Zealand. Operational data and personal accounts were used alongside a range of secondary data, to highlight how considerations outlined by Devlen [6] applied to three different clinical laboratory businesses operating in this post-earthquake context. Each of the laboratories had updated contingency plans, following a previous earthquake in September 2010. This appears to have helped the laboratories address many considerations outlined by Devlen [6], through prior planning or by being equipped to respond to unexpected contingencies. Contingency planning by two of the laboratories, CHL and SCL, appears to have been nested in a robust set of strategic approaches. For CHL, these approaches formed part of back-up systems needed to ensure they have a smooth 24 hour a day, seven day a week service available for the Emergency Department of Christchurch Hospital. SCL was able to decentralize its services, across a network of testing laboratories located in several different parts of New Zealand. SCL was responsible for a small portion of the testing market prior to the 2011 earthquake and this may have allowed them to be more flexible, as one part of a much wider and distributed network. MLS had centralized their services prior to the earthquake. These services had become co-located within a laboratory that was compromised by the earthquake. Much of MLS's testing was integrated within CHL buildings and processes. Although MLS continued to operate as part of the CDHB Integrate Health System, the arrangement was costly to sustain.

It is difficult to generalize details from this case study of three very different clinical laboratory services - especially when many of the contingencies faced by the laboratories were so difficult to predict. The current case study nonetheless highlights the importance of ensuring that clinical laboratories are firmly embedded within a wider business, or health sector, network. For $\mathrm{CHL}$, the CDHB Integrated Health System provided support via the surrounding health sector. The wider business network supporting SCL was provided by branches situated in Auckland, Ashburton and Dunedin. MLS also formed part of a limited business network, via their parent company. Interactions between CHL, SCL and their respective networks appear to have reflected a particular type of resilience to disaster events and other challenges to business continuity. Although the wider health sector network supporting CDHB was largely located within Canterbury and the wider business network supporting SCL was located elsewhere, both laboratories were able to leverage a range of associated financial, planning, administrative, logistical, and even infrastructural support. It is therefore recommended that wider, strategic approaches to supporting business resilience are mindful that clinical laboratories only function as part of a wider business and health sector network. The benefits of integration within these networks are paramount and cannot be taken for granted. Instead, the integrated resilience enjoyed by CHL and SCL required a particular balance between service delivery and financial feasibility.

In addition to highlighting the importance of wider organizational resilience, the current case study has demonstrated how the Devlen [6] business continuity model applies to clinical laboratories. Many considerations outlined by Devlen [6] were addressed to some extent by CHL, SCL and MLS. Each of these laboratory businesses maintained a very high degree of business continuity right through the first year of response and initial recovery from the Christchurch earthquake. However, the longerterm continuity of each laboratory business still appears to have depended on wider strategies reinforcing the resilience of entire health sector networks. It is therefore recommended that the Devlen [6] model is used to structure further case studies, but only alongside complementary models of health sector resilience which are beginning to emerge in both grey and academic literature.

\section{References}

1. Taylor K, George P, Deely J (2013) The impact of Christchurch earthquake on availability of diagnostic test results. The New Zealand medical Journal 126(11).

2. Forsman RW (1996) Why is the laboratory an afterthought for managed care organizations? Clinical Chemistry 42(5): 813-816.

3. Garcia LS (2013) Clinical laboratory management. American Society for Microbiology Press, Washington, DC.

4. Rodríguez H, Aguirre BE (2006) Hurricane Katrina and the healthcare infrastructure: A focus on disaster preparedness, response, and resiliency. Frontiers of Health Services Management 23(1): 13-23.

5. Franco C, Toner E, Waldhorn R, Maldin B, OToole T, et al. (2006) Systemic collapse: Medical care in the aftermath of Hurricane Katrina. Biosecurity and Bioterrorism: Biodefense Strategy, Practice, and Science, 4(2): 135146.

6. Devlen A (2009) How to build a comprehensive business continuity programme for a healthcare organization. Journal of Business Continuity \& Emergency Planning 4(1): 47-61.

7. Ardagh M, Deely J (2018) Rising from the Rubble: A health system's extraordinary response to the Canterbury earthquakes. Canterbury University Press. pp. 302.

8. Johnston DM, Standring S, Ronan K, Lindell M, Wilson T, et al. (2014) The 2010/2011 Canterbury Earthquakes: Context and Cause of Injury. Natural Hazards 73: 627-637.

9. Wood P, Robins P, Hare J (2010) Preliminary observations of the 2010 Darfield (Canterbury) Earthquakes: An introduction. Bulletin of the New Zealand Society for Earthquake Engineering 43(4): i-iv.

10. Quigley MC, Bastin S, Bradley BA (2013) Recurrent liquefaction in Christchurch, New Zealand, during the Canterbury earthquake sequence. Geology 41(4): 419-422.

11. Ardagh MW, Richardson SK, Robinson V, Than M, Gee P, et al. (2012) The initial health-system response to the earthquake in Christchurch, New Zealand, in February, 2011. The Lancet 379: 2109-2115.

12. Gullery C, Hamilton G (2015) Towards integrated person-centred healthcare - the Canterbury journey. Future Hospital Journal 2(2): 111116.

13. Musaad SMA, Herd G (2013) Point-of-care testing governance in New Zealand: A national framework. New Zealand Medical Journal 126(1383): 72-79.

14. (2010) Radio New Zealand. Industrial Action by Lab Workers to Resume. available at http://www.radionz.co.nz/news/national/57537/ 
industrial-action-by-lab-workers-to-resume (accessed 1 June 2017).

15. Taylor K, George P, Deely JM (2014) Laboratory turnaround times in response to an abrupt increase in specimen testing after a natural disaster. American Journal of Clinical Pathology 142: 35-42.

16. Schluter PJ, Hamilton GJ, Deely JM, Ardagh MW (2017) Impact of integrated health system changes, accelerated due to an earthquake, on

\section{ISSN: 2574-1241}

DOI: 10.26717/BJSTR.2020.26.004365

Joanne M Deely. Biomed J Sci \& Tech Res

(c) (P) This work is licensed under Creative

Submission Link: https://biomedres.us/submit-manuscript.php emergency department attendances and acute admissions: A Bayesian change-point analysis. British Medical Journal Open 6(5): e010709.

17. (2015) Resilient Health Care Net. About the Resilient Health Care Net, available at: http://www.resilienthealthcare.net/ (accessed 2 May 2017).

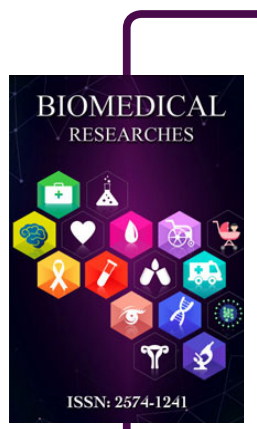

Assets of Publishing with us

- Global archiving of articles

- Immediate, unrestricted online access

- Rigorous Peer Review Process

- Authors Retain Copyrights

- Unique DOI for all articles 